\title{
Adoption of Preventive Behaviour Strategies and Public Perceptions About COVID-19 in Singapore
}

\author{
Semra Ozdemir ${ }^{*}$, Sean Ng $^{\circledR}$, Isha Chaudhry ${ }^{\circledR}$, Eric Andrew Finkelstein ${ }^{\circledR}$
}

\begin{abstract}
Background: The unprecedented severity of coronavirus disease 2019 (COVID-19) constitutes a serious public health concern. However, adoption of COVID-19-related preventive behaviours remain relatively unknown. This study investigated predictors of preventive behaviours.

Methods: An analytical sample of 897 Singaporean adults who were quota sampled based on age, gender, and ethnicity were recruited through a web-enabled survey. Outcomes were adoption of, or increased frequency of preventive behaviours (avoiding social events; avoiding public transport; reducing time spent shopping and eating out; wearing a mask in public; avoiding hospitals/clinics; keeping children out of school, washing hands/using sanitisers; keeping surroundings clean; avoiding touching public surfaces; working from/studying at home). Public perceptions regarding COVID-19 (chances of getting COVID-19; perceived likelihood of COVID-19-related intensive care unit (ICU) admission; government trust; self-efficacy; perceived appropriateness of COVID-19 behaviours; response efficacy), anxiety, and demographic characteristics (age; ethnicity; marital status; education; chronic conditions; current living arrangements) were investigated as predictors of preventive behaviours adopted during COVID-19 in binomial and ordered logistic regressions.

Results: Though adoption of preventive behaviours among Singaporeans varied, it was, overall, high, and consistent with government recommendations. Nearly a quarter reported moderate to severe anxiety (General Anxiety Disorder 7-item - GAD-7 scores). Respondents who perceived higher COVID-19 risks, had higher government trust, higher self-efficacy, and perceived that others acted appropriately reported increased adoption/frequency of preventive measures. The strongest indicator of behavioural change was response efficacy. Respondents who were older, highly educated, anxious and married reported higher adoption/frequency of preventive measures.

Conclusion: To successfully influence appropriate preventive behaviours, public health messages should highlight response efficacy, increase self-efficacy, and promote trust in governmental response. Focus should be on demographic segments with low adoptions, such as younger individuals and those with low education.

Keywords: COVID-19, Coronavirus, Preventive Behaviour Uptake, Public Perceptions, SARS-CoV-2, Singapore

Copyright: (C) 2022 The Author(s); Published by Kerman University of Medical Sciences. This is an open-access article distributed under the terms of the Creative Commons Attribution License (https://creativecommons.org/ licenses/by/4.0), which permits unrestricted use, distribution, and reproduction in any medium, provided the original work is properly cited.

Citation: Ozdemir S, Ng S, Chaudhry I, Finkelstein EA. Adoption of preventive behaviour strategies and public perceptions about COVID-19 in Singapore. Int J Health Policy Manag. 2022;11(5):579-591. doi:10.34172/ijhpm.2020.199
\end{abstract}

Article History:

Received: 9 June 2020

Accepted: 4 October 2020

ePublished: 20 October 2020
*Correspondence to:
Semra Ozdemir
Email:
semra.ozdemir@duke-nus.edu.sg

\section{Key Messages}

Implications for policy makers

- Although adoption of individual preventive behaviours varied, adoption of the preventive measures among Singaporeans was, overall, high.

- The most widely adopted measures to avoid coronavirus disease 2019 (COVID-19) were avoiding or cancelling social events and reducing time spent shopping/eating out, consistent with the recommendations at the time.

- Response efficacy, self-efficacy, and government trust are important predictors of preventive behaviour adoption.

Implications for the public

Our findings underlined the importance of response efficacy, self-efficacy and government trust in motivating public adoption of preventive behaviours. Public health messages should focus on demographic segments with low adoptions, such as younger individuals and those with low education. These results will provide governments with a deeper understanding of the factors associated with preventive behaviour adoption during a pandemic, ensuring that the most appropriate interventions are put in place to best safeguard the health of the public. 


\section{Background}

The coronavirus disease 2019 (COVID-19) pandemic, originally detected in the Hubei province of China in late 2019, has since spread across the globe. ${ }^{1-4}$ The infection and fatality rates of COVID-19 are significantly higher than that of influenza - particularly in the elderly and individuals with pre-existing health conditions - making this outbreak a matter of grave public health concern. ${ }^{5,6}$ With pharmaceutical interventions for the prevention and treatment of COVID-19 still in development, ${ }^{7}$ non-pharmaceutical preventive measures such as personal protective equipment, promotion of preventive behaviours, and social quarantines are relied on to prevent spread. ${ }^{8-10}$ In Singapore, the setting of this study, these measures were conveyed to the public through extensive coverage by national news networks ${ }^{11-13}$ and citizen journalism sites. ${ }^{14-16}$ However, evidence on factors predicting the adoption of COVID-19 preventive behaviours, particularly in a Singaporean context, is limited. This underlines the importance of research focusing on a better understanding of the predictors of behavioural adoption in large-scale pandemics. Findings are expected to aid in the development of public health messages focused on increasing the adoption of preventive measures during future large-scale pandemics.

Literature on past pandemics and current COVID-19 highlights the importance of public perceptions in influencing the adoption of preventive behaviours. When individuals reported higher self-efficacy ${ }^{17,18}$ (ie, they believed that they could prevent an infection) and higher risk perception, ${ }^{19,20}$ greater engagement in preventive behaviours was reported. Conversely, when people perceived the risk of COVID-19 to be exaggerated or disproportionate to the threat, preventive behaviours including hand-washing and social distancing decreased $^{21}$. These results are consistent with the protection motivation theory (PMT) model, which proposes that individuals protect themselves based on several factors: perceived severity of event, probability of occurrence, perceived vulnerability, response efficacy, and self-efficacy. ${ }^{22}$

Adoption of preventive behaviours, however, was not consistent across all protective behaviours. Measures that were perceived to have better response efficacy such as frequent hand washing and mask wearing had higher rates of adoption compared to those that were viewed as less efficacious (ie, working from home), ${ }^{19}$ suggesting that response efficacy may play an important role in the adoption of preventive behaviours. Public perception regarding the source of the preventive measures, in this case the respective governments, has also been found to predict protective behaviour adoption - government trust was positively correlated with adoption of preventive measures. ${ }^{23}$ In all, extant literature suggests that influencing public perception regarding pandemics is necessary to increase adoption of the preventive measures. However - while important - public perceptions of the respective pandemics were not the only factors associated with the adoption of precautionary measures.

Generally, being female, ${ }^{17,24}$ older ${ }^{25}$ married,${ }^{26}$ having higher levels of education, ${ }^{19,24}$ and anxiety ${ }^{27,28}$ motivated positive behavioural changes during the COVID-19 pandemic. And while - to the best of our knowledge - there is little COVID-19 specific literature that examines the associations between positive behavioural changes and other demographic factors (ie, living arrangements, comorbidity) precedents from past pandemics demonstrate that living with young children ${ }^{29}$ or having comorbid disease $\mathrm{s}^{30,31}$ motivated preventive behaviours such as mask wearing and hand washing. And while there is little research done on the associations between living with elderly individuals and behavioural changes in pandemics, based on the increased risks of COVID-19 faced by the elderly, we expect that living with them would encourage behaviour change.

Building on available literature, the aims of this study were to examine Singaporean public perceptions towards COVID-19 and to identify predictors of preventive behaviours in response to COVID-19. We hypothesised that perceived appropriateness of COVID-19 behaviours and high perceived COVID-19 risks, self-efficacy, response efficacy and government trust would be associated with adoption of preventive measures. We also hypothesized that being older, married, female, having higher education, higher anxiety, having pre-existing conditions and living with young children or the elderly would be associated with increased adoption of preventive behaviours. The survey was administered to an adult sample of Singapore's general population during the initial stages of the COVID-19 pandemic. At the time of the survey, 683 (March 31, 2020) to 2631 (April 14, 2020) confirmed cases and 10 COVID-19 related deaths were reported in Singapore, ${ }^{32}$ significantly lower than in many countries (ie, America, China). ${ }^{32}$ It should also be noted the Singapore government implemented a circuit breaker, akin to a partial national lockdown, on seventh of April during our fieldwork. Restrictions at the time of the survey included, but were not limited to, travel advisories to infected countries, 14-day quarantines for people showing symptoms, cancelling of events with more than 250 people, social distancing of 1 metre, and requiring those with symptoms to wear masks ${ }^{33,34}$ The analytical sample included only the respondents who completed the survey before the circuit breaker became effective.

\section{Methods}

Study Settings

A web-enabled survey was administrated by a market research company to their panel members between March 31, 2020 and April 14, 2020, and quota sampled based on Singapore's census figures. Soft demographic quotas were also applied to age, gender and ethnicity with a $+/-5 \%$ error margin. The inclusion criteria of this study included being (1) aged 21 years old and above (the legal age of majority in Singapore) and (2) a resident of Singapore (ie, citizen, permanent resident, or work/dependent pass holder) at the time of the survey. A quota sample was taken based on gender, age, and ethnicity to ensure that the final sample would be nationally representative. Written informed consent was provided by all respondents. Respondents who completed the survey received small incentives via a point-based reward system paid by the survey company.

The Singapore government implemented a circuit breaker, 
akin to a partial national lockdown, on seventh of April during our fieldwork. Restrictions included, but were not limited to mandatory working/studying from home arrangements, tighter workplace measures for essential workers, limited travel, controlled access to areas susceptible to crowds (ie, supermarkets), and restrictions on social gatherings with those outside one's own household. ${ }^{35}$

\section{Key Variables}

\section{Preventive Behaviours (Outcomes)}

As a measure of the preventive behaviours adopted during COVID-19, respondents answered "yes," "no," or "not applicable" to the question "in the past week, have you followed any of the strategies below (deliberately cancelled or avoided social events; avoided taking public transport; reduced time spent shopping; reduced frequency/duration spent eating out; wore a surgical mask in public; deliberately cancelled a doctor's appointment or avoided hospitals or clinics; kept any of your children out of school) to reduce the risk of COVID-19 infection?" For all the activities listed above except for "kept any of your children out of school," "no" and "not applicable" responses were merged under "no." For the variable "kept any of your children out of school," those who responded "not applicable" were excluded from the analysis since they may not have school-aged children.

To examine preventive behaviours for which individuals could adopt increased frequency, respondents responded "same as usual," "slightly more than usual" or "much more than usual" to the question "in the past week, how often did you follow any of the strategies below (washed hands with soap or use hand sanitisers; kept your surroundings clean; avoided touching public surfaces; worked from/studied at home) to reduce the risk of COVID-19 infection?"

\section{Public Perception of COVID-19 in Singapore (Independent Variables)}

Three questions were used to gauge risk perceptions regarding the severity of COVID-19. First, respondents answered the question "what do you think your chances of getting COVID-19 are in comparison to regular flu (influenza)?" Response options included "much lower than the flu," "slightly lower than the flu," "same as the flu," "slightly higher than the flu" or "much higher than the flu." Additionally, respondents also responded to the perceived likelihood of intensive care unit (ICU) admission and the likelihood of dying upon getting COVID-19 on a 4 -item Likert scale ranging from "very unlikely," to "very likely."

To investigate the general public opinion regarding the COVID-19 outbreak in Singapore, respondents responded "strongly disagree," "somewhat disagree," "neither agree nor disagree," "somewhat agree" or "strongly agree" to the statements: "I think the government will be successful in containing the spread of COVID-19," "I think that if I am careful, I can reduce my chances of getting COVID-19," and "I think people in Singapore are overly worried/paranoid about COVID-19."

Public perception regarding the effectiveness of preventive behaviours in reducing COVID-19 risk was examined through the question "how effective do you think the following strategies are: avoiding social events; avoiding public transportation; reducing time spent shopping; reducing frequency/duration spent eating out; wearing a mask in public avoiding hospitals or clinics; keeping children out of school; washing hands with soap or using hand sanitizers frequently; keeping your surroundings cleaner; avoid touching public surfaces; working from/studying at home. Response choices were "not effective," "somewhat effective," or "very effective."

General Anxiety Disorder 7-item Scale (Independent Variable) Respondent anxiety was measured using the General Anxiety Disorder 7-item (GAD-7) Scale. The GAD-7 is a wellestablished and internal consistent scale (Cronbach's $\alpha=0.89$ in an adult general population $\left.{ }^{36}\right)$. The scale contains a total of 7-items measured on 4-point Likert scale examining anxiety symptoms over the last 2 weeks ("not at all," "several days," "over half the days," "nearly every day").

\section{Respondent Demographics (Independent Variables)}

Respondents were asked to report their age, gender, marital status, level of education, number of chronic health conditions and current living arrangements (ie, if they lived with an elderly person or young children). Although we did not have a specific hypothesis related to ethnicity, we included a dummy variable indicating Chinese ethnicity (vs. other race/ ethnic groups) since Singapore consists of multiple ethnic groups, and some studies found that ethnicity was a predictor for adoption of preventive behavior. ${ }^{37,38}$

\section{Statistical Analysis}

We first presented the descriptive summary statistics for demographic characteristics, anxiety, preventive behaviours adopted, and perceptions about COVID-19. Binomial logistic regression was performed for preventive behaviours that were adopted during COVID-19 (ie, deliberately cancelling or avoiding social events, avoiding public transportation, reducing time spent shopping, reducing frequency/ duration spent eating out, wearing a surgical mask in public, deliberately cancelling a doctor's appointment or avoiding hospitals or clinics, keeping children out of school). Ordered logistic regression was performed for preventive behaviours for which individuals could adopt increased frequency (ie, washing hands with soap or use hand sanitisers, keeping your surroundings clean, avoiding touching public surfaces, working from/studying at home).

We first ran univariable regression with each independent variable (mentioned above) and included only those that were significant at $10 \%$ level in the multivariable models. In case of high correlation between two independent variables (Pearson correlation coefficient $\geq 0.3$ ), one of the correlated variables were not included in the multivariable regressions. Independent variables included public perceptions regarding COVID-19: chances of getting COVID-19 in comparison to the regular flu (much higher or slightly higher vs. much lower, slightly lower, same), chances of being admitted to the ICU (very likely or somewhat likely vs. somewhat unlikely or very unlikely), chances of dying from COVID-19 (very 
likely or somewhat likely vs. somewhat unlikely or very unlikely), strong trust in COVID-19 related government policies (strongly agree vs. somewhat agree, neither agree/ disagree, somewhat or strongly disagree), believing that they can reduce their chances of getting COVID-19 (strongly or somewhat agree vs. neither agree/disagree, somewhat or strongly disagree), thinking that the people in Singapore are overly worried/paranoid about COVID-19 (strongly agree or somewhat agree vs. neither agree/disagree, somewhat disagree, strongly disagree), and the effectiveness of the respective preventive behaviour (very effective vs. somewhat effective or not effective).

We also included respondent demographics as part of independent variables: GAD-7 score, age categories 21-35, 36-50 (vs. over 50), married (vs. not), female (vs. male), higher education (university degree vs. lower), number of pre-existing chronic conditions, living with young children (vs. not), living with elderly (vs. not), and ethnicity (Chinese vs. non-Chinese).

We used STATA 16.1 for all analyses.

\section{Results}

Study Sample

Of the 1338 quota-sampled participants, 98 participants terminated the survey and 223 participants had recorded partial responses. Out of remaining 1017 participants, 120 participants completed the survey after the national partial lockdown was implemented and were therefore excluded from the analysis. This left us a final analytical sample of 897 participants.

\section{Respondent Characteristics}

About half of our respondents (47.6\%) were female. The majority (84.2\%) were Chinese with a median age of 40 years. There was a relatively uniform distribution of age groups, with $36.5 \%$ aged between 21 to 35 years old, $36.4 \%$ aged between 36 to 50 years old, and $28.1 \%$ aged $>50$ years old. Overall, our sample is generally representative of the national population ${ }^{39}$ in terms of gender (51\% female) and age (median age 41.1 years) but over-represents the Chinese ethnicity (74.3\%). The majority were married (55.0\%), university graduates $(60.7 \%)$ and were living with elderly ( $\geq 65$ years; $52.4 \%$ ). $36.4 \%$ of respondents reported living with children below 12 years old. Over one-third of the respondents (34.7\%) reported presence of at least one chronic condition with median (interquartile range, IQR) number of chronic conditions $2(1,3)$. 28.5\% of the respondents reported mild anxiety (GAD 5-9) and about a quarter $(23.8 \%)$ had moderate or severe anxiety (GAD score $\geq 10$ ) (Table 1).

\section{Public Perceptions of COVID-19 in Singapore}

Regarding perceptions of COVID-19 risk, $45.0 \%$ of respondents believed that they had "slightly higher" or "much higher" chances of getting COVID-19 compared to the regular flu (influenza) while $47.0 \%$ believed that they were either "somewhat likely" or "very likely" to be admitted to the ICU following COVID-19 infection. 30.1\% of respondents felt that their likelihood of dying from COVID-19 was "very likely" or
Table 1. Sample Characteristics and Risk Perceptions About COVID-19, $\mathrm{N}=897$

\begin{tabular}{lc}
\hline \multicolumn{1}{c}{ Respondent Characteristics } & No. (\%) \\
\hline Female & $427(47.6)$ \\
Age (y) & \\
Mean (SD) & $42(12.8)$ \\
Median (IQR) & $40(32.0,52.0)$ \\
$>50$ & $252(28.1)$ \\
$21-35$ & $327(36.5)$ \\
$36-50$ & $318(36.4)$ \\
Ethnicity & \\
Chinese & $755(84.2)$ \\
Malay & $64(7.1)$ \\
Indian + others & $78(8.7)$ \\
Married & $493(55.0)$ \\
Education &
\end{tabular}

Below university (no formal education, primary, secondary, vocational/ITE, JC/polytechnic/diploma/do not know/not sure)

University or above

353 (39.3)

living arrangement

Living with elderly (aged $\geq 65$ ), yes $\quad 470$ (52.4)

Living with young children ( $\leq 12)$, yes $\quad 327$ (36.4)

Chronic health conditions

At least one chronic health condition, yes 311 (34.7)

Median (IQR) for those with chronic conditions $2(1.0,3.0)$

Mean (SD) for those with chronic conditions 2 (1.7)

GAD-7 Score

Median (IQR) $\quad 5(1.0,9.0)$

Mean (SD)

$6(5.5)$

Mild anxiety (score: 5-9)

256 (28.5)

Moderate anxiety (score: 10-14) 151 (16.8)

Severe anxiety (score: $\geq 15$ )

$63(7.0)$

Public Perceptions of COVID-19 in Singapore

Chances of getting COVID-19 compared to the regular

Flu

Much lower than the flu, slightly lower than the flu, same as the flu

$493(55.0)$

Slightly higher than the flu, much higher than the flu

Perceived likelihood of COVID-19-related ICU admission

Very unlikely, somewhat unlikely $\quad 475$ (53.0)

Very likely, somewhat likely $\quad 422$ (47.0)

Likelihood of Death from COVID-19

Very unlikely, somewhat unlikely

627 (69.9)

Very likely, somewhat likely

$270(30.1)$

I think the government will be successful in containing

the spread of COVID-19

Neither agree/disagree, somewhat disagree, strongly

disagree, somewhat agree

$678(75.6)$

Strongly agree

I think that if I am careful, I can reduce my chances of getting COVID-19

Neither agree/disagree, somewhat disagree, strongly disagree

218 (24.3)

Strongly agree, somewhat agree

$679(75.7)$

I think that people in Singapore are overly worried/ paranoid about COVID-19

Neither agree/disagree, somewhat disagree, strongly disagree

$574(64.0)$

Strongly agree, somewhat agree $323(36.0)$

Abbreviations: COVID-19, coronavirus disease 2019; IQR, interquartile range; SD, standard deviation; ITE, Institute of Technical Education; JC, junior college; ICU, intensive care unit.

All figures are in percentages; Due to rounding, percentages may not add up to $100 \%$.

*IQR: inter-quartile range represents 25 th and 75 th percentile. 
"somewhat likely" upon getting COVID-19 (Table 1).

Nearly a quarter of the respondents (24.4\%) indicated that they "strongly agreed" that the government would successfully contain the spread of COVID-19. The majority of respondents (75.7\%) either "somewhat agreed" or "strongly agreed" that they would be able to reduce their chances of getting COVID-19 if they were careful. Only about a third of respondents (36.0\%) "somewhat agreed" or "strongly agreed" that people in Singapore were overly worried or paranoid about COVID-19 (Table 1).

\section{Adopted Preventive Behaviours}

The most adopted strategies to avoid COVID-19 in the past week were reducing time spent shopping (86.2\%), reducing the frequency and duration spent eating out (86.1\%) and cancelling or avoiding social events $(82.8 \%)$. Keeping children out of school (43.2\%) and cancelling a doctor's appointment or avoiding hospitals and clinics (33.8\%) were the least adopted measures (Table 2).

To reduce risk of COVID-19 infection in the past week, respondents increased the frequency "much more than usual" of: washing hands with soap/using hand sanitisers (39.4\%), keeping clean surroundings (26.6\%), avoiding touching public areas (39.0\%) and working/studying from home (32.4\%) (Table 2).

Washing of hands was considered to be the most effective strategy in reducing risk of getting COVID-19, with 61.7\% considering it "very effective." Keeping children out of school (27.9\%) was perceived as the least effective strategy (Table 2).
Predictors of Preventive Behaviours Adopted During COVID-19 Perceived risk of COVID-related death was highly correlated with perceived risk of COVID-related ICU admission (Pearson correlation coefficient $=0.57$ ). Living with young children was highly correlated with being married (Pearson correlation coefficient $=0.40$ ). Thus, perceived risk of COVIDrelated death and living with children were dropped from the multivariable analyses. Being female was not significant in univariable regressions $(P>.10$ for all $)$ and was therefore excluded from the multivariable analyses.

Public Perceptions Regarding COVID-19 and Adoption of Preventive Behaviours

Respondents who thought their chances of getting COVID-19 were higher in comparison to regular influenza had higher odds of cancelling social events and reducing time spent eating out. Similarly, perceived likelihood of COVID-19-related ICU admission was associated with higher odds of reducing time spent shopping and eating out and wearing masks in public. Government trust, however, did not significantly predict the adoption of any new preventive behaviours.

Respondents who agreed that they could reduce their chances of getting COVID-19 if they were careful had higher odds of cancelling social events, reducing their time spent shopping and eating out. Those who agreed that Singaporeans were overly concerned or paranoid regarding COVID-19 had lower odds of reducing time spent shopping or eating out.

Of note, higher perceived response efficacy was a significant predictor for adoption of all preventive behaviours

Table 2. Preventive Behaviour Strategies and Their Response Efficacy, $N=897$

\begin{tabular}{|c|c|c|}
\hline & No. (\%) & Response Efficacy (Very Effective), No. (\%) \\
\hline \multicolumn{3}{|c|}{ Adopted Preventive Behaviour Strategy, Yes } \\
\hline Cancelled or avoided social events & $743(82.8)$ & $419(46.7)$ \\
\hline Avoided public transportation & $395(44.0)$ & $275(30.7)$ \\
\hline Reduced the frequency/duration spent shopping & $773(86.2)$ & $332(37.0)$ \\
\hline Reduced the frequency/duration spent eating out & $772(86.1)$ & $327(36.5)$ \\
\hline Wore a surgical mask in public & $516(57.5)$ & $330(36.8)$ \\
\hline Avoided hospitals or clinics & $303(33.8)$ & $318(35.5)$ \\
\hline Kept children out of school ${ }^{\mathrm{a}}$ & $184(43.2)$ & 119 (27.9) \\
\hline \multicolumn{3}{|c|}{ Preventive Behaviours That Could Be Adopted With Increased Frequency } \\
\hline \multicolumn{3}{|l|}{ Washing hands with soap or using hand sanitisers } \\
\hline Same as usual & $155(17.3)$ & \\
\hline Slightly more than usual & $389(43.4)$ & $553(61.7)$ \\
\hline Much more than usual & $353(39.4)$ & \\
\hline \multicolumn{3}{|l|}{ Keeping your surroundings cleaner } \\
\hline Same as usual & $258(28.8)$ & \\
\hline Slightly more than usual & $400(44.6)$ & 407 (45.4) \\
\hline Much more than usual & $239(26.6)$ & \\
\hline \multicolumn{3}{|l|}{ Avoid touching public surfaces } \\
\hline Same as usual & $180(20.1)$ & \\
\hline Slightly more than usual & $367(40.9)$ & $445(49.6)$ \\
\hline Much more than usual & $350(39.0)$ & \\
\hline \multicolumn{3}{|l|}{ Working from/studying at home } \\
\hline Same as usual & $344(38.4)$ & \\
\hline Slightly more than usual & $262(29.2)$ & $417(46.5)$ \\
\hline Much more than usual & $291(32.4)$ & \\
\hline
\end{tabular}

${ }^{a} \mathrm{~N}=426$ as" Not applicable" responses for the variable "Keeping children out of school" were removed as the respondents may not have school-aged children. 
(cancelling social events, avoiding public transport, reducing time spent shopping and eating out, wearing masks in public, avoiding hospitals and clinics and keeping children out of school). Response efficacy also had the largest odds ratios in predicting all preventive behaviours except cancelling social events (Table 3 ).

Personal Characteristics and Adoption of Preventive Behaviours

In relation to demographic variables that predicted the adoption of preventive behaviours during COVID-19, it is important to note that higher anxiety (GAD-7 scores) predicted higher odds of cancelling social events, avoiding public transport, wearing masks in public, avoiding hospitals or clinics or keeping children out of school.

Additionally, respondents who were aged 21-35 compared to those $>50$ years old, had higher odds of wearing their masks in public. Chinese, compared to non-Chinese participants, had lower odds of avoiding public transport and keeping children out of school. Married respondents, compared to those who were not married, also reported higher odds of cancelling social events, avoiding public transport, reducing time spent shopping and eating out and wearing their masks in public. Respondents with university education or above, compared to those with below university education, had higher odds of cancelling social events, avoiding public transport, wearing masks in public and avoiding hospitals or clinics. The higher the number of chronic conditions reported by respondents, the higher their odds were of avoiding hospitals and clinics. Those living with the elderly had higher odds of reducing their time spent shopping compared to respondents not living with elderly individuals (Table 3 ).

Predictors of Preventive Behaviours That Could Be Adopted With Increased Frequency During COVID-19

Public Perception of COVID-19 and Preventive Behaviours That Could Be Adopted With Increased Frequency

Respondents who thought their chances of getting COVID-19 were higher in comparison to regular influenza did not significantly predict increased frequency of any preventive behaviours. The perceived likelihood of COVID-19-related ICU admission was associated with an increased frequency of cleaning the environment. Individuals who agreed that the government would be successful in containing the spread of COVID-19 had higher of odds of increasing the frequency of washing hands. Additionally, respondents who agreed that they could reduce their chances of getting COVID-19 if they were careful, had higher odds of avoiding touching surfaces in public and working/studying from home. However, those who agreed that Singaporeans were overly concerned or paranoid regarding COVID-19 had lower odds of increasing the frequency of washing their hands and avoiding touching public surfaces.

Similarly, response efficacy also predicted all the examined preventive behaviours that could be adopted with increased frequency (washing hands, cleaning environment, avoid touching public surfaces and working/studying from home) and had the largest odds ratios for all preventive behaviours that could be adopted with increased frequency (Table 4).

Personal Characteristics and Preventive Behaviours That Could Be Adopted With Increased Frequency

Higher scores on the GAD-7 were also predictive of increased frequency in many preventive behaviours including washing hands, cleaning environment, avoiding touching public surfaces.

Additionally, those aged 21-35, compared to those $>50$, reported lower odds of washing hands, cleaning environment, avoid touching public surfaces but higher odds of working/ studying from home. Participants aged 36-50, compared to those $>50$, also had lower odds of washing their hands. Ethnicity (Chinese vs. non-Chinese) was associated with lower odds of avoiding touching public places. Married respondents, compared to those who were not, was not associated with increased/decreased odds of increasing frequency of any preventive behaviours. Those who were university educated and above, compared to those who had below university level education, had higher odds of increasing their frequency of washing hands, avoiding touching public surfaces and working/studying from home. Number of reported chronic conditions, however, was only associated with the increased odds of avoiding touching public places. Respondents who lived with elderly individuals - compared to those who did not - had lower odds of working/studying from home (Table 4).

\section{Discussion}

This study aimed to examine public perceptions toward COVID-19 and to identify predictors of COVID-19 preventive behaviours in Singapore. Results suggested that though adoption of individual preventive behaviours varied, adoption of the preventive behaviours among Singaporeans was, overall, high. Respondents who perceived higher risks, government trust, believed they could decrease their risk of COVID-19, perceived appropriateness of COVID-19 behaviours, and, and had higher response efficacy reported increased adoption and/or frequency of preventive measures. Regarding respondent characteristics, older individuals, those who are educated, anxious, and married were more likely to adopt or increase frequency of preventive measures. Importantly, about $24 \%$ of the sample reported moderate (GAD-7: 10-14) or severe (GAD-7: $\geq 15$ ) anxiety.

\section{Adoption of Preventive Behaviours}

Consistent with government advisories restricting social interaction, ${ }^{40}$ the most widely adopted measures to avoid COVID-19 were avoiding or cancelling social events (82.8\%) and reducing time spent shopping/eating out $(86.2 \% / 86.1 \%)$. It should be noted, however, that among these widely adopted preventive behaviours, adoption of mask wearing was not as widespread (57.5\%). This could be because, unlike recommendations regarding social distancing, government advisories regarding mask wearing have not been consistent or clear. Earlier advisories suggested that mask wearing was of limited use and practicability, and only recommended for sick individuals ${ }^{41,42}$ - in contrast with later measures that recommended wearing masks in public. ${ }^{43}$ Our 
Table 3. Binomial Logistic Regressions on the Predictors of Adoption of Preventive Behaviours, N = 897 (Odds Ratios)

\begin{tabular}{|c|c|c|c|c|c|c|c|}
\hline & $\begin{array}{l}\text { Cancel Social } \\
\text { Events }\end{array}$ & $\begin{array}{c}\text { Avoid Public } \\
\text { Transport }\end{array}$ & $\begin{array}{l}\text { Reduce Time } \\
\text { Spent Shopping }\end{array}$ & $\begin{array}{l}\text { Reduce Time Spent } \\
\text { Eating out }\end{array}$ & $\begin{array}{l}\text { Wearing Masks } \\
\text { in Public }\end{array}$ & $\begin{array}{l}\text { Avoiding Hospitals } \\
\text { or Clinics }\end{array}$ & $\begin{array}{l}\text { Keeping Children } \\
\text { out of School* }\end{array}$ \\
\hline \multicolumn{8}{|c|}{ Public Perceptions of COVID-19 in Singapore } \\
\hline \multicolumn{8}{|c|}{ Chances of getting COVID-19 compared to influenza (ref: Same/lower) } \\
\hline Higher (slightly higher, much higher) & 1.39 & 1.19 & 1.16 & 1.49 & 1.10 & 1.11 & 0.98 \\
\hline $95 \% \mathrm{Cl}$ & $0.95 ; 2.02$ & $0.89 ; 1.59$ & $0.77 ; 1.74$ & $0.98 ; 2.27$ & $0.82 ; 1.47$ & $0.82 ; 1.50$ & $0.63 ; 1.51$ \\
\hline$P$ value & 0.09 & 0.24 & 0.49 & 0.06 & 0.52 & 0.49 & 0.92 \\
\hline \multicolumn{8}{|c|}{ Likelihood of ICU admission if you get COVID-19 (ref: unlikely) } \\
\hline Likely (very likely, somewhat likely) & 1.31 & 1.25 & 1.63 & 1.77 & 1.47 & 1.10 & 1.07 \\
\hline $95 \% \mathrm{Cl}$ & $0.89 ; 1.92$ & $0.92 ; 1.68$ & $1.06 ; 2.49$ & $1.15 ; 2.73$ & $1.09 ; 1.98$ & $0.81 ; 1.50$ & $0.68 ; 1.69$ \\
\hline$P$ value & 0.17 & 0.15 & 0.03 & 0.01 & 0.01 & 0.53 & 0.76 \\
\hline \multicolumn{8}{|c|}{ Government will be successful in containing the spread of COVID-19 (ref: disagree/no opinion) } \\
\hline Agree (strongly agree, somewhat agree) & 0.77 & 0.98 & 1.01 & 0.83 & 1.12 & 0.89 & 1.18 \\
\hline $95 \% \mathrm{Cl}$ & $0.49 ; 1.21$ & $0.69 ; 1.38$ & $0.60 ; 1.70$ & $0.50 ; 1.38$ & $0.79 ; 1.59$ & $0.62 ; 1.27$ & $0.71 ; 1.95$ \\
\hline$P$ value & 0.25 & 0.89 & 0.96 & 0.46 & 0.53 & 0.51 & 0.52 \\
\hline \multicolumn{8}{|c|}{ I think that if I am careful, I can reduce my chances of getting COVID-19 (ref: disagree/no opinion) } \\
\hline Agree (strongly agree, somewhat agree) & 2.00 & 0.86 & 1.97 & 1.88 & 0.93 & 0.86 & 0.85 \\
\hline$P$ value & 0.00 & 0.39 & 0.00 & 0.01 & 0.69 & 0.42 & 0.53 \\
\hline \multicolumn{8}{|c|}{ I think that people in Singapore are overly worried/paranoid about COVID-19 (ref: disagree/no opinion) } \\
\hline Agree (strongly agree, somewhat agree) & 0.88 & 1.07 & 0.69 & 0.48 & 0.86 & 1.25 & 1.36 \\
\hline $95 \% \mathrm{Cl}$ & $0.60 ; 1.29$ & $0.79 ; 1.45$ & $0.46 ; 1.05$ & $0.32 ; 0.72$ & $0.64 ; 1.16$ & $0.91 ; 1.70$ & $0.88 ; 2.10$ \\
\hline$P$ value & 0.52 & 0.67 & 0.08 & 0.00 & 0.33 & 0.17 & 0.17 \\
\hline \multicolumn{8}{|c|}{ Effectiveness of strategies in reducing risk of getting the COVID-19 virus (ref: not effective/somewhat effective) } \\
\hline Very effective & 1.87 & 3.55 & 4.22 & 3.28 & 3.44 & 2.55 & 4.19 \\
\hline $95 \% \mathrm{Cl}$ & $1.25 ; 2.78$ & $2.59 ; 4.87$ & $2.41 ; 7.38$ & $1.94 ; 5.54$ & $2.50 ; 4.72$ & $1.87 ; 3.49$ & $2.57 ; 6.84$ \\
\hline$P$ value & 0.00 & 0.00 & 0.00 & 0.00 & 0.00 & 0.00 & 0.00 \\
\hline \multicolumn{8}{|c|}{ Participant Demographics } \\
\hline GAD (anxiety) & 1.05 & 1.04 & 1.03 & 1.03 & 1.04 & 1.09 & 1.08 \\
\hline $95 \% \mathrm{Cl}$ & $1.01 ; 1.09$ & $1.01 ; 1.07$ & $0.99 ; 1.07$ & $0.99 ; 1.07$ & $1.01 ; 1.07$ & $1.06 ; 1.12$ & $1.03 ; 1.12$ \\
\hline$P$ value & 0.02 & 0.01 & 0.19 & 0.21 & 0.01 & 0.00 & 0.00 \\
\hline
\end{tabular}




\begin{tabular}{|c|c|c|c|c|c|c|c|}
\hline & $\begin{array}{l}\text { Cancel Social } \\
\text { Events }\end{array}$ & $\begin{array}{l}\text { Avoid Public } \\
\text { Transport }\end{array}$ & $\begin{array}{l}\text { Reduce Time } \\
\text { Spent Shopping }\end{array}$ & $\begin{array}{l}\text { Reduce Time Spent } \\
\text { Eating out }\end{array}$ & $\begin{array}{l}\text { Wearing Masks } \\
\text { in Public }\end{array}$ & $\begin{array}{l}\text { Avoiding Hospitals } \\
\text { or Clinics }\end{array}$ & $\begin{array}{l}\text { Keeping Children } \\
\text { out of School* }\end{array}$ \\
\hline \multicolumn{8}{|c|}{ Age categories (ref: $>50$ years old) } \\
\hline $21-35$ years old & 1.36 & 0.95 & 0.92 & 1.58 & 1.73 & 0.74 & 1.34 \\
\hline $95 \% \mathrm{Cl}$ & $0.78 ; 2.39$ & $0.62 ; 1.46$ & $0.51 ; 1.66$ & $0.86 ; 2.88$ & $1.13 ; 2.64$ & $0.48 ; 1.16$ & $0.71 ; 2.53$ \\
\hline$P$ value & 0.28 & 0.83 & 0.78 & 0.14 & 0.01 & 0.19 & 0.37 \\
\hline $36-50$ years old & 0.70 & 0.89 & 0.91 & 1.24 & 1.36 & 0.89 & 0.74 \\
\hline $95 \% \mathrm{Cl}$ & $0.44 ; 1.11$ & $0.61 ; 1.32$ & $0.53 ; 1.56$ & $0.72 ; 2.13$ & $0.93 ; 1.98$ & $0.60 ; 1.32$ & $0.41 ; 1.31$ \\
\hline$P$ value & 0.13 & 0.57 & 0.72 & 0.43 & 0.11 & 0.55 & 0.30 \\
\hline \multicolumn{8}{|l|}{ Ethnicity (ref: Non-Chinese) } \\
\hline Chinese & 0.67 & 0.57 & 0.91 & 0.74 & 1.04 & 0.93 & 0.53 \\
\hline $95 \% \mathrm{Cl}$ & $0.38 ; 1.19$ & $0.38 ; 0.85$ & $0.50 ; 1.65$ & $0.40 ; 1.38$ & $0.70 ; 1.56$ & $0.62 ; 1.41$ & $0.30 ; 0.92$ \\
\hline$P$ value & 0.17 & 0.01 & 0.76 & 0.35 & 0.84 & 0.75 & 0.03 \\
\hline \multicolumn{8}{|l|}{ Marital status (ref: Not married) } \\
\hline Married & 1.65 & 1.75 & 2.07 & 3.24 & 1.43 & 1.15 & 0.71 \\
\hline $95 \% \mathrm{Cl}$ & $1.09 ; 2.49$ & $1.26 ; 2.43$ & $1.31 ; 3.27$ & $2.01 ; 5.23$ & $1.03 ; 1.99$ & $0.82 ; 1.61$ & $0.42 ; 1.20$ \\
\hline$P$ value & 0.02 & 0.00 & 0.00 & 0.00 & 0.03 & 0.41 & 0.20 \\
\hline University and above & 2.07 & 2.41 & 1.43 & 1.35 & 1.46 & 1.51 & 1.21 \\
\hline $95 \% \mathrm{Cl}$ & $1.41 ; 3.03$ & $1.76 ; 3.30$ & $0.94 ; 2.17$ & $0.89 ; 2.07$ & $1.08 ; 1.98$ & $1.09 ; 2.08$ & $0.77 ; 1.92$ \\
\hline$P$ value & 0.00 & 0.00 & 0.10 & 0.16 & 0.02 & 0.01 & 0.41 \\
\hline Number of chronic conditions & 1.06 & 1.07 & 0.96 & 1.14 & 1.08 & 1.19 & 0.89 \\
\hline $95 \% \mathrm{Cl}$ & $0.92 ; 1.23$ & $0.96 ; 1.19$ & $0.83 ; 1.11$ & $0.95 ; 1.36$ & $0.96 ; 1.20$ & $1.07 ; 1.33$ & $0.78 ; 1.03$ \\
\hline$P$ value & 0.41 & 0.21 & 0.57 & 0.15 & 0.20 & 0.00 & 0.11 \\
\hline \multicolumn{8}{|l|}{ Living with elderly (ref: No) } \\
\hline Yes & 0.95 & 0.98 & 1.47 & 1.40 & 0.89 & 0.77 & 0.91 \\
\hline $95 \% \mathrm{Cl}$ & $0.64 ; 1.40$ & $0.72 ; 1.33$ & $0.96 ; 2.25$ & $0.91 ; 2.16$ & $0.66 ; 1.21$ & $0.56 ; 1.05$ & $0.57 ; 1.44$ \\
\hline$P$ value & 0.79 & 0.89 & 0.08 & 0.13 & 0.45 & 0.10 & 0.68 \\
\hline Constant & 1.16 & 0.27 & 1.13 & 0.90 & 0.29 & 0.18 & 0.66 \\
\hline $95 \% \mathrm{Cl}$ & $0.50 ; 2.70$ & $0.14 ; 0.53$ & $0.46 ; 2.78$ & $0.35 ; 2.29$ & $0.15 ; 1.58$ & $0.09 ; 0.36$ & $0.24 ; 1.83$ \\
\hline$P$ value & 0.74 & 0.00 & 0.79 & 0.82 & 0.00 & 0.00 & 0.43 \\
\hline Log likelihoods & -373.61 & -542.61 & -321.69 & -314.82 & -549.29 & -519.00 & -251.95 \\
\hline
\end{tabular}

Abbreviations: COVID-19, coronavirus disease 2019; GAD, general anxiety disorder; ICU, intensive care unit.

$95 \%$ confidence intervals presented below odds ratios in italics.

* $N=426$ as "Not applicable" responses for the variable "Keeping children out of school" were removed as the respondents may not have school-aged children. 
Table 4. Ordered Logistic Regressions on the Predictors of Preventive Behaviours that can be Adopted with Increased Frequency, $\mathrm{N}=897$ (Proportional Odds Ratios)

\begin{tabular}{|c|c|c|c|c|}
\hline & Washing Hands & Cleaning Environment & Avoid Touching Public Surfaces & Working/Studying From Home \\
\hline \multicolumn{5}{|c|}{ Public Perceptions of COVID-19 in Singapore } \\
\hline \multicolumn{5}{|c|}{ Chances of getting COVID-19 compared to the flu (influenza) (ref: Same/lower) } \\
\hline Higher (slightly higher, much higher) & 1.22 & 1.20 & 1.12 & 0.99 \\
\hline $95 \% \mathrm{Cl}$ & $0.94 ; 1.57$ & $0.93 ; 1.54$ & $0.86 ; 1.45$ & $0.77 ; 1.28$ \\
\hline$P$ value & 0.14 & 0.16 & 0.40 & 0.95 \\
\hline \multicolumn{5}{|c|}{ Likelihood of ICU Admission if you get COVID-19 (ref: unlikely) } \\
\hline Likely (very likely, somewhat likely) & 1.05 & 1.26 & 1.00 & 1.22 \\
\hline $95 \% \mathrm{Cl}$ & $0.81 ; 1.37$ & $0.97 ; 1.64$ & $0.76 ; 1.31$ & $0.93 ; 1.58$ \\
\hline$P$ value & 0.71 & 0.08 & 0.99 & 0.15 \\
\hline \multicolumn{5}{|c|}{ Government Will be Successful in Containing the Spread of COVID-19 (ref: disagree/no opinion) } \\
\hline Agree (Strongly agree, somewhat agree) & 1.48 & 1.28 & 1.09 & 1.24 \\
\hline$P$ value & 0.02 & 0.12 & 0.62 & 0.17 \\
\hline \multicolumn{5}{|c|}{ I think that if I am careful, I can reduce my chances of getting COVID-19 (ref: disagree/no opinion) } \\
\hline Agree (Strongly agree, somewhat agree) & 1.19 & 1.05 & 1.32 & 1.51 \\
\hline $95 \% \mathrm{Cl}$ & $0.88 ; 1.61$ & $0.78 ; 1.42$ & $0.97 ; 1.80$ & $1.11 ; 2.06$ \\
\hline$P$ value & 0.27 & 0.75 & 0.07 & 0.01 \\
\hline \multicolumn{5}{|c|}{ I think that people in Singapore are overly worried/paranoid about COVID-19 (ref: disagree/no opinion) } \\
\hline Agree (Strongly agree, somewhat agree) & 0.75 & 1.18 & 0.70 & 1.01 \\
\hline $95 \% \mathrm{Cl}$ & $0.58 ; 0.98$ & $0.91 ; 1.53$ & $0.54 ; 0.92$ & $0.77 ; 1.32$ \\
\hline$P$ value & 0.03 & 0.22 & 0.01 & 0.93 \\
\hline \multicolumn{5}{|c|}{ Effectiveness of strategies in reducing risk of getting the COVID-19 Virus (ref: not effective/somewhat effective) } \\
\hline Very effective & 2.66 & 2.99 & 4.73 & 2.87 \\
\hline$P$ value & 0.00 & 0.00 & 0.00 & 0.00 \\
\hline \multicolumn{5}{|c|}{ Participant Demographics } \\
\hline GAD (anxiety) & 1.03 & 1.06 & 1.05 & 1.01 \\
\hline $95 \% \mathrm{Cl}$ & $1.00 ; 1.05$ & $1.03 ; 1.09$ & $1.02 ; 1.07$ & $0.99 ; 1.04$ \\
\hline$P$ value & 0.05 & 0.00 & 0.00 & 0.28 \\
\hline \multicolumn{5}{|l|}{ Age categories (ref: $>50$ years old) } \\
\hline $21-35$ years old & 0.60 & 0.69 & 0.71 & 1.43 \\
\hline $95 \% \mathrm{Cl}$ & $0.41 ; 0.88$ & $0.47 ; 1.00$ & $0.48 ; 1.03$ & $0.98 ; 2.08$ \\
\hline$P$ value & 0.01 & 0.05 & 0.07 & 0.06 \\
\hline $36-50$ years old & 0.65 & 0.80 & 0.81 & 1.32 \\
\hline $95 \% \mathrm{Cl}$ & $0.46 ; 0.91$ & $0.57 ; 1.13$ & $0.58 ; 1.15$ & $0.94 ; 1.85$ \\
\hline$P$ value & 0.01 & 0.21 & 0.24 & 0.11 \\
\hline \multicolumn{5}{|l|}{ Ethnicity (ref: Non-Chinese) } \\
\hline Chinese & 0.87 & 0.88 & 0.71 & 0.79 \\
\hline $95 \% \mathrm{Cl}$ & $0.61 ; 1.24$ & $0.61 ; 1.25$ & $0.50 ; 1.03$ & $0.55 ; 1.12$ \\
\hline$P$ value & 0.43 & 0.47 & 0.07 & 0.18 \\
\hline \multicolumn{5}{|l|}{ Marital status (ref: Not married) } \\
\hline Married & 1.01 & 1.23 & 1.18 & 1.16 \\
\hline $95 \% \mathrm{Cl}$ & $0.76 ; 1.34$ & $0.93 ; 1.63$ & $0.88 ; 1.58$ & $0.87 ; 1.55$ \\
\hline$P$ value & 0.95 & 0.16 & 0.26 & 0.31 \\
\hline \multicolumn{5}{|l|}{ Educational level (ref: Below university level) } \\
\hline University and above & 1.40 & 1.18 & 1.88 & 2.44 \\
\hline
\end{tabular}


Table 4. Continued

\begin{tabular}{|c|c|c|c|c|}
\hline & Washing Hands & Cleaning Environment & Avoid Touching Public Surfaces & Working/Studying From Home \\
\hline \multicolumn{5}{|c|}{ Participant Demographics } \\
\hline Number of chronic conditions & 1.06 & 1.04 & 1.10 & 1.01 \\
\hline $95 \% \mathrm{Cl}$ & $0.96 ; 1.16$ & $0.94 ; 1.14$ & $0.99 ; 1.21$ & $0.92 ; 1.11$ \\
\hline$P$ value & 0.26 & 0.44 & 0.07 & 0.83 \\
\hline \multicolumn{5}{|l|}{ Living with elderly (ref: No) } \\
\hline Yes & 0.90 & 0.91 & 0.96 & 0.79 \\
\hline $95 \% \mathrm{Cl}$ & $0.69 ; 1.18$ & $0.70 ; 1.19$ & $0.73 ; 1.26$ & $0.60 ; 1.03$ \\
\hline$P$ value & 0.45 & 0.48 & 0.77 & 0.08 \\
\hline Cut 1 & -1.01 & 0.00 & -0.43 & 0.97 \\
\hline $95 \% \mathrm{Cl}$ & $-1.63 ;-0.39$ & $-0.60 ; 0.60$ & $-1.05 ; 0.18$ & $0.37 ; 1.58$ \\
\hline Cut 2 & 1.18 & 2.14 & 1.77 & 2.38 \\
\hline $95 \% \mathrm{Cl}$ & $0.56 ; 1.80$ & $1.53 ; 2.76$ & $1.14 ; 2.39$ & $1.76 ; 3.01$ \\
\hline Log likelihoods & -988.52 & -899.14 & -841.85 & -895.70 \\
\hline
\end{tabular}

Abbreviations: COVID-19, coronavirus disease 2019; GAD, general anxiety disorder; ICU, intensive care unit. $95 \%$ confidence intervals presented below proportional odds ratio in italics.

results demonstrated that, in accordance to past literature, recommended measures have to be consistent and clear to encourage adoption.

Lowest adoption rates were reported for avoiding hospitals/ clinics (33.8\%), avoiding public transport (44\%) and keeping children out of school (43.2\%). There may be several reasons for these findings. It is possible that the reticence among Singaporeans regarding avoiding public transport may be due to the unclear, inconsistent information regarding the safety of utilising public transport during the COVID-19 pandemic. ${ }^{44-46}$ We also have to consider the essentialness of public transport in Singapore. ${ }^{47}$ Due to low car ownership in the country, a significant number of Singaporean families are reliant on public transport for daily, essential activities, making avoiding them unfeasible. The same argument of necessity can be applied to the low avoidance rates of hospitals/clinics - they may also be seen as unavoidable for individuals with health conditions. The choice of parents' to keep their children in school can also be explained by earlier government reports recommending them to do so. ${ }^{48,49}$ These findings suggest that clear and consistent information is necessary to influence appropriate preventive behaviours.

Regarding preventive behaviours that could be adopted with increased frequency, the majority of our respondents increased their frequency of hygienic practices (a consistently highlighted government recommendation) to reduce their risks of getting COVID-19. However, of note is a significant percentage of respondents who did not increase their frequency of working or studying from home (38.4\%). This may be because work-from-home arrangements are a luxury not afforded to many essential jobs (eg, those in the service sectors, teachers). Telecommuting was also not widely implemented in Singapore prior to the COVID-19 pandemic, ${ }^{50}$ and adoption may be slow.

Predictors of Preventive Behaviours

In support of our hypotheses, perceived risks related to
COVID-19 were found to be associated with the adoption of some preventive behaviours. These findings can be understood within the context of PMT, which states broadly - that the higher the perceived risks and vulnerability felt by the public, the higher the adoption of preventive behaviours. ${ }^{51,52}$ However, many preventive behaviours in this study were not predicted by perceived risks. This discrepancy may be due to confusions regarding the severity of COVID-19 risk. Specifically, there is - at present - a lack of scientific consensus across geological regions regarding the risk and severity of the virus. ${ }^{53-55}$ This, combined with misinformation prevalent in social media sites, ${ }^{56}$ may have precipitated large divides among the population regarding risk and severity of COVID-19. In support of our working hypothesis, results indicate significant discrepancies among respondents, with $55 \%$ perceiving their risks of contracting COVID-19 to be lower or the same as the normal flu (influenza). These results may have several important policy implications. First, they suggest that greater efforts may be required to combat misinformation. Second, they reinforce the argument that clear and consistent information throughout the pandemic is necessary for the public to motivate appropriate preventive behaviours.

As expected, ${ }^{23}$ results indicated that government trust predicted increased frequency of some preventive measures. A potential explanation for this finding may be that when governments are viewed as trustworthy, their measures are also seen as dependable, which in turn encourages the adoption of their recommendations. It should be noted, however, that government trust did not consistently predict the adoption and increased frequency of many preventive behaviours. While unexpected, this may be due to high baseline level of governmental trust already prevalent among Singaporeans. ${ }^{57,58}$ Nonetheless, these findings underline the importance of government trust toward ensuring public adoption of the preventive measures.

Supporting our hypothesis, individuals with higher levels 
of self-efficacy were more likely to adopt and increase the frequency of their preventive behaviours. This association between self-efficacy (ie, I can decrease my risk of infection) and adoption of preventive behaviours has been consistently underlined in literature, ${ }^{17,18}$ suggesting that the promotion of self-efficacy should be an important factor of consideration for educational interventions and public health messages.

Consistent with our hypotheses, response efficacy was also found to be an important predictor of preventive behaviours response efficacy predicted the adoption of all the respective preventive behaviours. It also had the largest odds ratios indicating that response efficacy had the strongest association with adoption of preventive behaviours. These findings are expected, and support PMT, which suggests that when faced with a threat to health (ie, COVID-19), the level of response efficacy of the preventive measure directly predicts its adoption. 59,60 These strong findings are of particular consequence as they demonstrate that the response efficacy play an essential role in increasing the adoption and frequency of the preventive measures. For increased public adoption of preventive measures, educational programs and public health messages must focus on the effectiveness of their preventive measures.

A quarter of the sample reported moderate to severe anxiety which warrants for further assessment and referral to a mental health specialist. These results suggest that anxiety could be a potential problem among general population during a large pandemic like COVID-19. Comparable to extant literature, we found that anxiety, older age, higher education, and marital status predicted the adoption and frequency of some preventive behaviours. However, given their particular vulnerability to COVID-19, the lack of associations between number of chronic conditions and preventive behaviours must be noted. Our results underline segments of population that could be targeted by tailored public health messages to promote the adoption of preventive measures.

\section{Significance and Implications}

Overall, the main strength of this study was its ability to pinpoint the significant drivers of behaviour adoption during a large-scale pandemic of unprecedented severity. It should also be noted that while this study was conducted in Singapore, its findings may also be generalizable to other Asian countries with similar societal, cultural and governmental structures (ie, countries with obedient, collectivistic populations such as Japan, China, etc). ${ }^{61}$ Our findings serve to increase governmental preparedness for future pandemics and also to provide important lessons for most countries in designing public health messages directed towards increasing the public adoption of preventive measures.

\section{Study Limitations and Future Research}

Our findings have to be taken in the context of several limitations. First, our findings may not be generalizable to individualistic societies. For example, studies from individualistic societies compared to the results from our study show distinctively lower adoption rates of many preventive behaviours. ${ }^{62,63}$ While examining the impact that culture may have on the adoption of preventive measures is beyond the scope of this study, future studies may consider a multicountry sample with participants recruited across different cultural regions. Additionally, no reliability analyses were conducted on the author-designed questions - it is possible that responses may not correlate with actual behaviour. Future studies should include (if possible) validated measures of COVID-19 perceptions. Finally, our sample overrepresented highly educated respondents (only $12.3 \%$ of our respondents reported not having at least college-level education (Institute of Technical Education; ITE and below). This is consistent with most web-enabled surveys as they tend to attract individuals with higher education. However, conducting an online survey enabled us to collect time-sensitive information much faster than other methods.

\section{Conclusion}

By examining public perception regarding COVID-19 and the predictors of preventive behaviours adopted by the Singaporean public, we found that to influence appropriate preventive behaviours, preventive measures have to be consistent, accurate, and clear. Additionally, to ensure consistent adoption of preventive measures, government programs should focus on promoting trust in government response, self-efficacy, and underline the effectiveness of respective preventive behaviours. Particular focus should be on demographic segments with likely low adoption, such as younger individuals and those with lower education. The study findings are expected to aid in increasing governmental preparedness for future outbreaks and help in developing educational programs and designing public health messages directed at increasing the adoption of preventive behaviours.

\section{Acknowledgements}

We would like to thank Dr. Chetna Malhotra and Dr. Irene Teo for their comments on the survey instrument.

\section{Ethical issues}

This study was exempted from review by the National University of Singapore Institutional Review Board (Application Reference Number: S-20-085).

\section{Competing interests}

Authors declare that they have no competing interests.

\section{Authors' contributions}

SO: Conceptualisation and design of study, data analysis, drafting of manuscript. SNYW: Drafting of manuscript (Introduction, methods, results, discussion). IC: Data analyses, and review and revision of manuscript. EAF: Review and revision of manuscript.

\section{Funding}

This project is funded by Lien Centre for Palliative Care (LCPC Research N-911-000-030-091), Duke-NUS Medical School.

\section{References}

1. Ahmad T, Khan M, Haroon, et al. COVID-19: zoonotic aspects. Travel Med Infect Dis. 2020;36:101607. doi:10.1016/j.tmaid.2020.101607

2. Wu Z, McGoogan JM. Characteristics of and important lessons from the coronavirus disease 2019 (COVID-19) outbreak in China: summary of a report of 72314 cases from the Chinese Center for Disease Control and Prevention. JAMA. 2020;323(13):1239-1242. doi:10.1001/jama.2020.2648

3. Bedford J, Enria D, Giesecke J, et al. COVID-19: towards controlling 
of a pandemic. Lancet. 2020;395(10229):1015-1018. doi:10.1016/ s0140-6736(20)30673-5

4. Singhal T. A review of coronavirus disease-2019 (COVID-19). Indian J Pediatr. 2020;87(4):281-286. doi:10.1007/s12098-020-03263-6

5. Yi Y, Lagniton PNP, Ye S, Li E, Xu RH. COVID-19: what has been learned and to be learned about the novel coronavirus disease. Int $J$ Biol Sci. 2020;16(10):1753-1766. doi:10.7150/ijbs.45134

6. Liu Y, Gayle AA, Wilder-Smith A, Rocklöv J. The reproductive number of COVID-19 is higher compared to SARS coronavirus. $J$ Travel Med. 2020;27(2). doi:10.1093/jtm/taaa021

7. Lythgoe MP, Middleton P. Ongoing clinical trials for the management of the COVID-19 pandemic. Trends Pharmacol Sci. 2020;41(6):363382. doi:10.1016/j.tips.2020.03.006

8. Sim SW, Moey KS, Tan NC. The use of facemasks to prevent respiratory infection: a literature review in the context of the Health Belief Model. Singapore Med J. 2014;55(3):160-167. doi:10.11622/ smedj.2014037

9. Vaughan E, Tinker T. Effective health risk communication about pandemic influenza for vulnerable populations. Am J Public Health. 2009;99 Suppl 2:S324-332. doi:10.2105/ajph.2009.162537

10. Truman BI, Tinker T, Vaughan E, et al. Pandemic influenza preparedness and response among immigrants and refugees. Am J Public Health. 2009;99 Suppl 2:S278-286. doi:10.2105/ ajph.2008.154054

11. Cheong D. Coronavirus: Most workplaces to close, schools will move to full home-based learning from next week, says PM Lee. The Strait Times. April 3, 2020. https://www.straitstimes.com/singapore/health/ most-workplaces-to-close-schools-will-move-to-full-home-basedlearning-from-next.

12. Wei AC. What Are Some of the New Rules at Workplaces from May 12 as Singapore Eases Tightened Covid-19 Circuit Breaker Measures. The Straits Times. May 9, 2020. https://www.straitstimes.com/ singapore/new-rules-from-may-12-as-singapore-eases-tightenedcovid-19-circuit-breaker-measures

13. The Straits Times. Coronavirus: Safe Distancing Rules Kick in, Failure to Sit or Queue $1 \mathrm{~m}$ Apart from Others Could Land You a Fine or Jail Term. The Straits Times. March 27, 2020. https://www.straitstimes. com/singapore/coronavirus-safe-distancing-rules-kick-in-failure-tosit-or-queue-1m-apart-from-others.

14. Kurohi R. No More Bubble Tea Shops and other New COVID-19 Measures. AsiaOne. April 21, 2020. https://www.asiaone.com/ singapore/no-more-bubble-tea-shops-and-other-new-covid-19measures.

15. Ling S. Netizens Condemn Travellers who Disregard Travel Advisories as it May Put Singaporeans' Lives at Risk for COVID-19. The Online Citizen. March 25, 2020. https://www.onlinecitizenasia. com/2020/03/25/netizens-condemn-travellers-who-disregard-traveladvisories-as-it-may-put-singaporeans-lives-at-risk-for-covid-19/.

16. The Online Citizen. COVID-19: S'pore Set to Close Workplaces Except Essential Services and Key Sectors, Implement Full HomeBased Learning Starting Next Week. The Online Citizen. April 3, 2020. https://www.onlinecitizenasia.com/2020/04/03/covid-19-sporeset-to-close-workplaces-except-essential-services-and-key-sectorsimplement-full-home-based-learning-starting-next-week/.

17. Yıldırım M, Güler A. COVID-19 severity, self-efficacy, knowledge, preventive behaviors, and mental health in Turkey. Death Stud. 2020:1-8. doi:10.1080/07481187.2020.1793434

18. Kebede Y, Yitayih Y, Birhanu Z, Mekonen S, Ambelu A. Knowledge, perceptions and preventive practices towards COVID-19 early in the outbreak among Jimma university medical center visitors, Southwest Ethiopia. PLoS One. 2020;15(5):e0233744. doi:10.1371/journal. pone.0233744

19. Lee M, You M. Psychological and behavioral responses in South Korea during the early stages of coronavirus disease 2019 (COVID-19). Int J Environ Res Public Health. 2020;17(9). doi:10.3390/ijerph17092977

20. Ahmad M, Iram K, Jabeen G. Perception-based influence factors of intention to adopt COVID-19 epidemic prevention in China. Environ Res. 2020;190:109995. doi:10.1016/j.envres.2020.109995

21. Imhoff R, Lamberty P. A bioweapon or a hoax? the link between distinct conspiracy beliefs about the coronavirus disease (COVID-19) outbreak and pandemic behavior. Soc Psychol Personal Sci. 2020. doi:10.1177/1948550620934692

22. Rogers RW. A protection motivation theory of fear appeals and attitude change1. J Psychol. 1975;91(1):93-114. doi:10.1080/00223 980.1975.9915803

23. Clark C, Davila A, Regis M, Kraus S. Predictors of COVID-19 voluntary compliance behaviors: an international investigation. Glob Transit. 2020;2:76-82. doi:10.1016/j.glt.2020.06.003

24. Zhong BL, Luo W, Li HM, et al. Knowledge, attitudes, and practices towards COVID-19 among Chinese residents during the rapid rise period of the COVID-19 outbreak: a quick online cross-sectional survey. Int J Biol Sci. 2020;16(10):1745-1752. doi:10.7150/ijbs.45221

25. Li S, Feng B, Liao W, Pan W. Internet use, risk awareness, and demographic characteristics associated with engagement in preventive behaviors and testing: cross-sectional survey on COVID-19 in the United States. J Med Internet Res. 2020;22(6):e19782. doi:10.2196/19782

26. Niu Z, Wang T, Hu P, et al. Chinese public engagement in preventive and intervening health behaviors during the early breakout of COVID-19: Cross-sectional study. J Med Internet Res. 2020;22(8): e19995. doi:10.2196/19995

27. Bacon AM, Corr PJ. Coronavirus (COVID-19) in the United Kingdom: a personality-based perspective on concerns and intention to selfisolate. Br J Health Psychol. 2020. doi:10.1111/bjhp.12423

28. Harper CA, Satchell LP, Fido D, Latzman RD. Functional fear predicts public health compliance in the COVID-19 pandemic. Int J Ment Health Addict. 2020:1-14. doi:10.1007/s11469-020-00281-5

29. Agüero F, Adell MN, Pérez Giménez A, López Medina MJ, Garcia Continente $X$. Adoption of preventive measures during and after the 2009 influenza A (H1N1) virus pandemic peak in Spain. Prev Med. 2011;53(3):203-206. doi:10.1016/j.ypmed.2011.06.018

30. Davis MD, Stephenson N, Lohm D, Waller E, Flowers P. Beyond resistance: social factors in the general public response to pandemic influenza. BMC Public Health. 2015;15:436. doi:10.1186/s12889-0151756-8

31. Stephenson N, Davis M, Flowers P, MacGregor C, Waller E. Mobilising "vulnerability" in the public health response to pandemic influenza. Soc Sci Med. 2014;102:10-17. doi:10.1016/j.socscimed.2013.11.031

32. Worldometers. COVID-19 Coronavirus Pandemic. 2020; https://www. worldometers.info/coronavirus/\#countries. Accessed August 4, 2020.

33. Wei TT, Khalik S. Covid-19: S'pore Rolls out More Measures Including Limiting, Where Possible, Size of Gatherings to 250 People; Workplace Distancing. The Straits Times; 2020. https:// www.straitstimes.com/singapore/health/covid-19-singapore-rolls-outmore-measures-including-limiting-where-possible-the.

34. Government of Singapore. Corrections and Clarifications Regarding Falsehoods Published by States Times Review on COVID-19 Situation. https://www.gov.sg/article/factually-clarifications-onfalsehoods-posted-by-str-on-covid-19-situation. Published 2020.

35. Government of Singapore. Circuit Breaker Extension and Tighter Measures: What you Need to Know. https://www.gov.sg/article/circuitbreaker-extension-and-tighter-measures-what-you-need-to-know. Accessed May 27, 2020. Published 2020.

36. Spitzer RL, Kroenke K, Williams JB, Löwe B. A brief measure for assessing generalized anxiety disorder: the GAD-7. Arch Intern Med. 2006;166(10):1092-1097. doi:10.1001/archinte.166.10.1092

37. Barr M, Raphael B, Taylor M, et al. Pandemic influenza in Australia: using telephone surveys to measure perceptions of threat and willingness to comply. BMC Infect Dis. 2008;8:117. doi:10.1186/14712334-8-117

38. Rubin GJ, Amlôt R, Page L, Wessely S. Public perceptions, anxiety, and behaviour change in relation to the swine flu outbreak: cross sectional telephone survey. BMJ.2009;339:b2651.doi:10.1136/bmj.b2651

39. Singapore Department of Statistics. Population Trends 2019. https://www.singstat.gov.sg/-/media/files/publications/population/ population2019.pdf. Published 2019.

40. Government of Singapore. Updates on COVID-19 (Coronavirus Disease 2019) Local Situation. Government of Singapore; 2020.

41. Goh T. Wuhan Virus: Masks Should be used Only by Those Who are Unwell. The Straits Times. January 31, 2020. https://www.straitstimes. com/singapore/health/masks-should-be-used-only-by-those-whoare-unwell. 
42. Khalik S. Wuhan Virus: Why it is Still Safe to Attend Events with Large Crowds. The Straits Times. February 1, 2020. https://www. straitstimes.com/singapore/why-it-is-still-safe-to-attend-events-withlarge-crowds.

43. lau J. Over 200 People Caught for Breaching Safe Distancing Rules, 80 Didn't Wear Masks Outside Homes. The Straits Times. April 20, 2020. https://www.straitstimes.com/singapore/health/over-200people-caught-for-breaching-safe-distancing-rules-80-didnt-wearmasks.

44. Chee K. Coronavirus: Singapore Confirms 2 New Local Infections; 1 Appears to Have no Link to Previous Cases. The Straits Times. February 6, 2020. https://www.straitstimes.com/singapore/health/ coronavirus-singapore-confirms-two-more-cases-bringing-total-to-30.

45. Goh T. Wuhan Virus: One Patient Took Public Transport but no Cause for Alarm, Says Don. The Straits Times. January 25, 2020. https:// www.straitstimes.com/singapore/health/one-patient-took-publictransport-but-no-cause-for-alarm-says-don.

46. Ang P. Coronavirus: All Commuters Have to Wear Masks on Public Transport, Even After Circuit Breaker Period, Says Khaw Boon Wan. The Online Citizen. April 11, 2020. https://www.straitstimes. com/singapore/coronavirus-all-commuters-have-to-wear-masks-onpublic-transport-says-khaw-boon-wan.

47. Chng S, Abraham C, White MP, Skippon S. To drive or not to drive? a qualitative comparison of car ownership and transport experiences in London and Singapore. Transportation Research Interdisciplinary Perspectives. 2019;2:100030. doi:10.1016/j.trip.2019.100030

48. Ang J. No Plans to Close Schools for Now, Says Education Minister Ong Ye Kung. The Straits Times; 2020.

49. Goh T, Ang J. Ong: No Need to Suspend School with Enhanced Measures. The Straits Times; 2020.

50. Zahraei SM, Choo C, Cheema W, Cheah L. Foresight study on singapore urban mobility: methodologies and preliminary insights. In: Cardin MA, Fong S, Krob D, Lui P, Tan Y, eds. Complex Systems Design \& Management Asia. Cham: Springer; 2016:135-145. doi:10.1007/978-3-319-29643-2_10

51. Sadique MZ, Edmunds WJ, Smith RD, et al. Precautionary behavior in response to perceived threat of pandemic influenza. Emerg Infect Dis. 2007;13(9):1307-1313. doi:10.3201/eid1309.070372

52. Abdulkareem SA, Augustijn EW, Filatova T, Musial K, Mustafa YT. Risk perception and behavioral change during epidemics: comparing models of individual and collective learning. PLoS One. 2020; 15(1):e0226483. doi:10.1371/journal.pone.0226483

53. Rudan I. A cascade of causes that led to the COVID-19 tragedy in Italy and in other European Union countries. J Glob Health. 2020; 10(1):010335. doi:10.7189/jogh-10-010335

54. Leung K, Wu JT, Liu D, Leung GM. First-wave COVID-19 transmissibility and severity in China outside Hubei after control measures, and second-wave scenario planning: a modelling impact assessment. Lancet. 2020;395(10233):1382-1393. doi:10.1016/ s0140-6736(20)30746-7

55. Khafaie MA, Rahim F. Cross-country comparison of case fatality rates of COVID-19/SARS-COV-2. Osong Public Health Res Perspect. 2020;11(2):74-80. doi:10.24171/j.phrp.2020.11.2.03

56. Government of Singapore. Clarifications: Misinformation, Rumours Regarding COVID-19. Government of Singapore; 2020. https://www. gov.sg/article/covid-19-clarifications. Accessed May 26, 2020.

57. Carlson M, Turner M. Public Support for Democratic Governance in Southeast Asia. Asian J Polit Sci. 2008;16(3):219-239. doi:10.1080/02185370802504076

58. Deurenberg-Yap M, Foo LL, Low YY, Chan SP, Vijaya K, Lee M. The Singaporean response to the SARS outbreak: knowledge sufficiency versus public trust. Health Promot Int. 2005;20(4):320326. doi:10.1093/heapro/dai010

59. Sharifirad G, Yarmohammadi P, Sharifabad MA, Rahaei Z. Determination of preventive behaviors for pandemic influenza $A$ / $\mathrm{H} 1 \mathrm{~N} 1$ based on protection motivation theory among female high school students in Isfahan, Iran. J Educ Health Promot. 2014;3:7. doi:10.4103/2277-9531.127556

60. Barnett DJ, Balicer RD, Lucey DR, et al. A systematic analytic approach to pandemic influenza preparedness planning. PLoS Med. 2005;2(12):e359. doi:10.1371/journal.pmed.0020359

61. Zhai Y. Values of deference to authority in Japan and China. Int $J$ Comp Sociol. 2017;58(2):120-139. doi:10.1177/0020715217694078

62. Seale H, Heywood AE, Leask J, et al. COVID-19 is rapidly changing: Examining public perceptions and behaviors in response to this evolving pandemic. PLoS One. 2020;15(6):e0235112. doi:10.1371/ journal.pone.0235112

63. Atchison C, Bowman L, Vrinten C, et al. Perceptions and behavioural responses of the general public during the COVID-19 pandemic: a cross-sectional survey of UK Adults. medRxiv. 2020. doi:10.1101/2020.04.01.20050039 